\title{
PERFIL E MOTIVOS DE NEGATIVAS DE FAMILIARES PARA DOAÇÃO DE ÓRGÃOS E TECIDOS PARA TRANSPLANTE
}

\author{
PROFILE AND REASONS FOR DENYING THE \\ DONATION OF ORGANS AND TISSUES FOR \\ TRANSPLANTS BY FAMILIARS
}

\section{PERFIL Y MOTIVOS DE LAS NEGATIVAS DE LOS FAMILIARES PARA DONACIÓN DE ÓRGANOS Y TEJIDOS PARA TRASPLANTE}

\author{
Renata Souza Aranda ${ }^{1}$ \\ Juliana Graciela Vestena Zillmer ${ }^{2}$ \\ Kamila Dias Gonçalves ${ }^{3}$ \\ Adrize Rutz Porto ${ }^{4}$ \\ Eduarda Rosado Soares 5 \\ Aline Kohler Geppert ${ }^{6}$
}

Como citar este artigo: Aranda RS, Zillmer JGV, Gonçalves KD, Porto AR, Soares ER, Geppert AK. Perfil e motivos de negativas de familiares para doação de órgãos e tecidos para transplante. Rev baiana enferm. 2018;32:e27560.

Objetivo: descrever o perfil de familiares e de potenciais doadores e os motivos de negativas para doação de órgãos e tecidos para transplantes. Método: estudo quantitativo, transversal, com coleta de dados por meio do formulário de entrevista familiar, realizado de 2008 a 2014, no Sul do Brasil. Resultados: o potencial doador predominantemente era do sexo masculino, entre 41 e 60 anos, casado, doador de córneas, e o familiar, de primeiro grau. Houve negativa familiar para doação de órgãos em 74,9\% do total de 630 prontuários. Entre as 472 negativas: 20,8\% por desconhecimento da vontade do potencial doador, 17,6\% pela convicção prévia de não ser um doador e 13,8\% por desacordo familiar. Conclusão: a descrição do perfil de familiares e de potenciais doadores e a identificação dos principais motivos da não doação podem contribuir para o planejamento e desenvolvimento de intervenções que estimulem a doação de tecidos e órgãos.

Descritores: Obtenção de Tecidos e Órgãos. Doador Cadáver. Família. Estudos Epidemiológicos. Enfermagem.

Objective: describe the profile of family members and potential donors, and the negative motives for organ and tissue donation for transplants. Method: quantitative, cross-sectional study with data collection through the family interview form, carried out from 2008 to 2014, in Southern Brazil. Results: the predominant potential donor was male, between 41 and 60 years, married, donor of corneas, and the first degree family member. There was a family

\footnotetext{
Enfermeira. Hospital Santa Casa de Pelotas. Pelotas, Rio Grande do Sul, Brasil.

Enfermeira. Doutora em Enfermagem. Professora Adjunta da Faculdade de Enfermagem da Universidade Federal de Pelotas. Pelotas, Rio Grande do Sul, Brasil. juzillmer@gmail.com

3 Enfermeira. Mestre em Ciências da Saúde. Orientadora Educacional da Escola SENAC Pelotas do curso Técnico de Enfermagem. Pelotas, Rio Grande do Sul, Brasil. 4 Enfermeira. Doutora em Enfermagem. Docente na Faculdade de Enfermagem e do Programa de Pós-graduação em Enfermagem da Universidade Federal de Pelotas. Pelotas, Rio Grande do Sul, Brasil. adrizeporto@gmail.com

Discente de enfermagem da Universidade Federal de Pelotas. Pelotas, Rio Grande do Sul, Brasil.

6 Enfermeira. Especialista em Saúde Pública com ênfase em Saúde da Família. Enfermeira da Prefeitura Municipal de Pelotas. Pelotas, Rio Grande do Sul, Brasil.
} 
denial for organ donation in $74.9 \%$ of the total of 630 medical records. Among the 472 denials were: $20.8 \%$ due to lack of knowledge of the willingness of the potential donor, $17.6 \%$ due to the previous conviction of not being a donor, and $13.8 \%$ due to family disagreement. Conclusion: describing the profile of family members and potential donors and identifying the main reasons for non-donation can contribute to the planning and development of interventions that stimulate the donation of tissues and organs.

Descriptors: Obtaining Tissues and Organs. Donor Corpse. Family. Epidemiological Studies. Nursing.

Objetivo: describir el perfil de los familiares y de potenciales donadores y los motivos que los llevan a no donar órganos y tejidos para trasplantes. Método: estudio cuantitativo, transversal, cuya recolecta de datos se hizo a través de un formulario de entrevista familiar, realizado de 2008 a 2014, en el Sur de Brasil. Resultados: el potencial donador era, predominantemente, del sexo masculino, entre 41 y 60 años, casado, donador de córneas, así como el familiar de primer grado. Hubo una negativa familiar para la donación de órganos en un 74,9\% del total de los 630 informes médicos. Entre las 472 negativas: el 20,8\% lo hace por desconocimiento de la voluntad de ser un potencial donador, el 17,6\% por la convicción previa de no ser un donador y, el 13,8\% por desacuerdo familiar. Conclusión: la descripción del perfil de los familiares y de potenciales donadores, así como la identificación de los principales motivos para no donar, pueden contribuir para el planeamiento y el desarrollo de intervenciones que estimulen la donación de tejidos y órganos.

Descriptores: Obtención de Tejidos y Órganos. Donador Cadáver. Familia. Estudios Epidemiológicos. Enfermería.

\section{Introdução}

O Brasil, ao longo dos anos, tem apresentado inúmeros avanços no processo de doação e transplante de órgãos e tecidos. Os avanços foram tanto no aperfeiçoamento de procedimentos e técnicas como também na formulação de leis e políticas públicas, que possibilitaram a criação do Sistema Nacional de Transplante ${ }^{(1)}$, um dos maiores programas públicos do mundo. O país ocupa o segundo lugar do mundo em número de transplantes realizados, financiados pelo Sistema Único de Saúde (SUS) ${ }^{(2)}$.

Como resultados desse programa, de 2010 a 2017, o Brasil tem reduzido a quantidade de pessoas que aguardam por transplante de órgão, devido à elevação da taxa de doadores efetivos. Em 2017, essa taxa cresceu 14\%, atingindo 16,6 por milhão de população (pmp), e decorreu do aumento de 3,8\% na taxa de notificação de potenciais doadores (51,6 pmp) e de 10,2\% na taxa de efetivação de doadores $(32,4 \%)$. Entre os estados, destacaram-se Santa Catarina (40,8 pmp) com aumento de 10,9\% e Paraná (38,0 pmp) com incremento de 26,2\%. Apenas Santa Catarina efetivou $50 \%$ dos potenciais doadores ${ }^{(2)}$.

Apesar dos avanços nas políticas públicas e do crescente número de doadores efetivos e concretização do transplante no Brasil, a oferta ainda não supera a demanda. Em alguns estados, esse número está aquém do esperado. Em dezembro de 2017, no país, havia 32.402 pessoas aguardando por um órgão e/ou tecido. Dentre os 24 estados brasileiros, São Paulo apresentou o maior número de pacientes na lista de espera (15.021), seguido de Minas Gerais, com 3.428, e Rio de Janeiro, com 1.918. Em relação ao Rio Grande do Sul, estão registrados 1.224 pacientes na lista de espera ${ }^{(2)}$.

Diante desse panorama, há inúmeros fatores que podem contribuir para a recusa nesse processo $^{(3)}$, entre eles a negativa dos familiares do potencial doador. Constatou-se que alguns dos principais fatores para a recusa dos familiares na doação de órgãos é o desconhecimento da vontade do familiar ${ }^{(4-6)}$. Outro fator também descrito na literatura foi o despreparo do profissional da saúde para abordar a família no momento da morte e da entrevista, por não ter informações suficientes, levando os familiares a não consentir a doação de órgãos ${ }^{(7-8)}$. A entrevista familiar é considerada a etapa mais importante do processo, sendo determinante na tomada de decisão quanto à opção dos familiares, ou não, pela doação de órgãos e tecidos ${ }^{(5,7)}$. 
Embora escassos, estudos ${ }^{(9-14)}$ sinalizam que a recusa na doação de órgãos e tecidos pelos familiares é a principal barreira para a não efetivação da doação, apontando motivos como falta de diálogo na família sobre o tema, desconhecimento do desejo do potencial doador, não compreensão do diagnóstico de morte encefálica, religiosidade, longo tempo de processo, decisão de único membro da família, despreparo do entrevistador, desejo de manter corpo íntegro, entre outros.

Para tanto, a relevância deste estudo pautou-se na importância de entender os motivos da decisão da recusa dos familiares em doar órgãos e/ou tecido e, assim, contribuir para o direcionamento e planejamento de intervenções futuras que possam concorrer para o aumento do número de doadores e de transplantes.

Diante desta problemática, o objetivo do presente estudo foi descrever o perfil de familiares e de potenciais doadores e os motivos de negativas para doação de órgãos e tecidos para transplantes.

\section{Método}

Trata-se de estudo quantitativo do tipo transversal, realizado por meio de coleta retrospectiva de dados secundários. Os registros alvos foram formulários de entrevista familiar contidos nos prontuários dos potenciais doadores abordados pela Comissão Intra-Hospitalar de Doação de Órgãos e Tecidos para Transplante (CIHDOTT) de um hospital de ensino de um município da Região Sul do Rio Grande do Sul, no qual o familiar negou a doação. A escolha desse hospital, para a realização do estudo, deveu-se ao fato de apresentar o maior número de doações da Região Sul do estado, desde sua implantação, a qual ocorreu em 2008, sendo, por isso, o início do período selecionado.

Os resultados foram obtidos por meio da análise de todos os prontuários dos potenciais doadores cadastrados na referida CIHDOTT, de dezembro de 2008 a novembro de 2014, que tiveram resposta negativa na abordagem de entrevista familiar. Nesse período, 630 prontuários de todos os potenciais doados do referido período foram pesquisados, mas, em um total de 472 prontuários, o familiar negou a doação.

O instrumento de coleta de dados foi um questionário pré-codificado, elaborado com base em um formulário para entrevista familiar da CIHDOTT com potenciais doadores. Realizou-se o estudo piloto na primeira quinzena de janeiro de 2016, o qual permitiu realizar a testagem final do questionário e a logística de trabalho. Posteriormente, foram realizados três encontros para capacitar os coletadores, acadêmicos de enfermagem. Nesse momento, fez-se a leitura do questionário e do manual de instruções sobre o preenchimento do instrumento, sendo esclarecidas as dúvidas com a finalidade de padronizar a coleta dos dados. Os campos preenchidos com informações ilegíveis ou que remetessem a dúvida foram considerados como ignorados. A coleta de dados teve início na segunda quinzena de janeiro de 2016 e foi concluída em março do mesmo ano.

A entrada dos dados foi realizada com o Software EpiData 3.1, com dupla digitação e checagem automática de consistência e amplitude. As variáveis foram analisadas de forma descritiva e estratificada com uso do Software Stata 11.1. Nessa análise foi calculada frequência simples e percentual. Quanto aos aspectos éticos, o estudo atendeu à Resolução n. 466/2012, do Conselho Nacional de Saúde. Foi encaminhado ao Comitê de Ética em Pesquisa de uma Universidade Pública e aprovado pelo Parecer n. 1.400.699, e submetido na Plataforma Brasil, recebendo o Certificado de Apresentação para Apreciação Ética (CAAE) n. 52679315.7.0000.5317.

\section{Resultados}

O estudo incluiu 472 formulários para entrevista familiar contidos nos prontuários dos potenciais doadores com negação da família para doação, dentre as 630 entrevistas familiares ocorridas no período de 2008 a 2014. A prevalência de negativa familiar para doação de órgãos foi de 74,9\%. No Gráfico 1, apresenta-se o número de negativas familiares de doação de órgãos e tecidos do potencial doador, por ano do óbito. 
Gráfico 1 - Distribuição das negativas familiares para doação, por ano de óbito do potencial doador. Pelotas, Rio Grande do Sul, Brasil - jan 2008-dez 2014 (N=472)

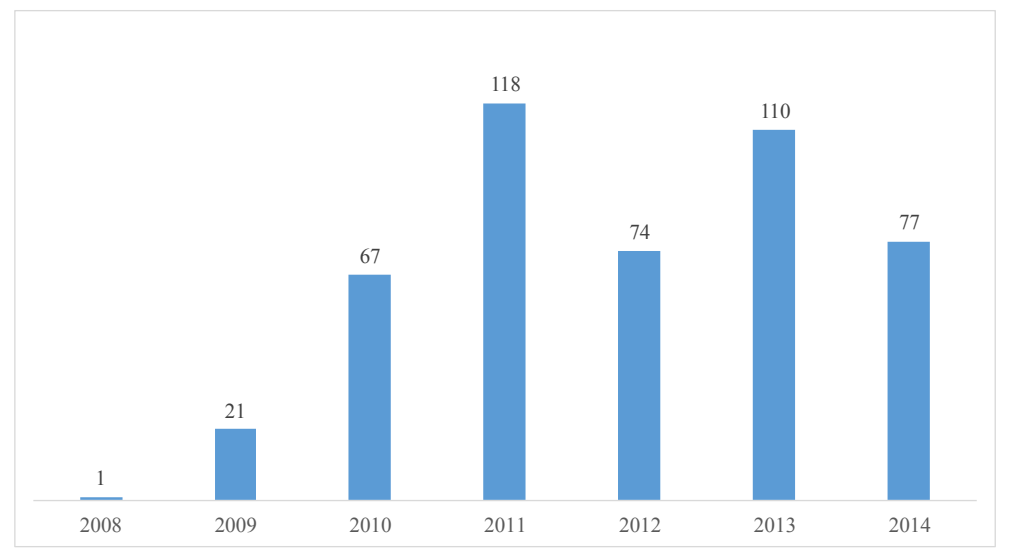

Fonte: Elaboração própria.

Nota: $\mathrm{n}<472$ pela ausência de informações.

A Tabela 1 apresenta os dados e de seus familiares bem como os motivos sociodemográficos dos potenciais doadores de negativa para a doação.

Tabela 1 - Distribuição dos dados sociodemográficos dos potenciais doadores e de seus familiares e motivos de negativa para doação. Pelotas, Rio Grande do Sul, Brasil - jan 2008-dez $2014(\mathrm{~N}=472)$

\begin{tabular}{|c|c|}
\hline Variáveis & n (\%) \\
\hline \multicolumn{2}{|l|}{ Sexo do potencial doador* } \\
\hline Masculino & $272(57,6)$ \\
\hline Feminino & $196(41,5)$ \\
\hline \multicolumn{2}{|c|}{ Idade do potencial doador (em anos)* } \\
\hline $0-20$ & $22(4,8)$ \\
\hline $21-40$ & $60(13,0)$ \\
\hline $41-60$ & $199(43,2)$ \\
\hline $61-80$ & $179(38,8)$ \\
\hline$>80$ & $1(0,2)$ \\
\hline \multicolumn{2}{|c|}{ Estado civil do potencial doador* } \\
\hline Casado & $138(29,2)$ \\
\hline Solteiro & $42(8,9)$ \\
\hline Divorciado/separado & $18(3,8)$ \\
\hline União estável & $14(3,0)$ \\
\hline \multicolumn{2}{|c|}{ Município do potencial doador* } \\
\hline Pelotas & $262(55,5)$ \\
\hline Capão do Leão & $13(2,8)$ \\
\hline Pinheiro Machado & $11(2,3)$ \\
\hline Canguçu & $10(2,1)$ \\
\hline Outros & $90(19,1)$ \\
\hline \multicolumn{2}{|l|}{ Tipo de óbito* } \\
\hline Parada cardiorrespiratória & $402(85,2)$ \\
\hline Morte Encefálica & $68(14,4)$ \\
\hline \multicolumn{2}{|l|}{ Sexo do familiar* } \\
\hline Masculino & $246(52,1)$ \\
\hline Feminino & $219(46,4)$ \\
\hline
\end{tabular}


Tabela 1 - Distribuição dos dados sociodemográficos dos potenciais doadores e de seus familiares e motivos de negativa para doação. Pelotas, Rio Grande do Sul, Brasil - jan 2008-dez $2014(\mathrm{~N}=472)$

(conclusão)

\begin{tabular}{lc}
\hline Variáveis & $\mathbf{n}(\mathbf{\%})$ \\
\hline Parentesco do familiar* & $218(48,8)$ \\
Pais, mães e filhos - 1o grau & $94(21,8)$ \\
Cônjuge, companheiro(a) & $88(19,6)$ \\
Irmãos, avós e netos - $2^{\circ}$ grau & $47(10,5)$ \\
Outros & \\
Tipo de doação* & $403(85,4)$ \\
Córneas & $47(10,0)$ \\
Córneas e órgãos & $20(4,2)$ \\
Múltiplos órgãos (exceto córneas) & \\
Motivos de negativa para doação & $98(20,8)$ \\
Desconhecimento da vontade do potencial doador & $83(17,6)$ \\
Convicção prévia da negação & $65(13,8)$ \\
Desacordo Familiar & $19(4,0)$ \\
Falta de condições emocionais & $16(3,4)$ \\
Dúvidas sobre a integridade do corpo & $10(2,1)$ \\
Não quis decidir sozinho(a) & $4(0,9)$ \\
Atraso no funeral & $3(0,6)$ \\
Causas Religiosas & \\
\hline
\end{tabular}

Fonte: Elaboração própria.

* n<472 pela omissão de informações.

A idade do potencial doador foi considerada pela ocasião do óbito. Os outros municípios do potencial doador são da região Sul e do mesmo estado. Os outros parentescos referiram-se a sobrinhos, tios, genros/noras, amigos, cunhados, primos.

Quanto ao tipo de óbito por sexo do potencial doador, no período de janeiro de 2008 a dezembro de 2014, 237 (59\%) homens e 161 (40\%) mulheres faleceram por parada cardiorrespiratória; 4 (1\%) respostas estavam em branco e 35 $(51,5 \%)$ mulheres e 33 (48,5\%) homens tiveram morte encefálica.

Os principais motivos de negativa para doação são apresentados, conforme o perfil do potencial doador e do familiar entrevistado, na Tabela 2.

Tabela 2 - Distribuição dos principais motivos de negativa para doação por variáveis sociodemográficas. Pelotas, Rio Grande do Sul, Brasil - jan 2008-dez 2014 (N=472)

(continua)

\begin{tabular}{l|c|c|c}
\hline \multirow{2}{*}{ Variáveis } & $\begin{array}{c}\text { Convicção prévia da não } \\
\text { doação }\end{array}$ & $\begin{array}{c}\text { Desconhecimento da } \\
\text { vontade do potencial } \\
\text { doador }\end{array}$ & $\begin{array}{c}\text { Desacordo } \\
\text { familiar }\end{array}$ \\
\cline { 2 - 4 } (n (\%) & & n (\%) \\
\hline $\begin{array}{l}\text { Parentesco } \\
\text { Pais e filhos }\end{array}$ & $35(43,2)$ & $60(61,9)$ & $30(48,4)$ \\
Cônjuge & $19(23,5)$ & $18(18,6)$ & $9(14,5)$ \\
Irmãos, avós e netos & $17(21)$ & $11(11,3)$ & $18(29)$ \\
Outros & $10(12,3)$ & $8(8,2)$ & $5(8,1)$ \\
Sexo do familiar & $49(59,8)$ & & $20(30,8)$ \\
Masculino & $33(40,2)$ & $57(58,2)$ & $45(69,2)$ \\
Feminino & & $41(41,8)$ &
\end{tabular}


Tabela 2 - Distribuição dos principais motivos de negativa para doação por variáveis sociodemográficas. Pelotas, Rio Grande do Sul, Brasil - jan 2008-dez 2014 (N=472)

(conclusão)

\begin{tabular}{l|c|c|c}
\hline \multirow{2}{*}{ Variáveis } & $\begin{array}{c}\text { Convicção prévia da não } \\
\text { doação }\end{array}$ & $\begin{array}{c}\text { Desconhecimento da } \\
\text { vontade do potencial } \\
\text { doador }\end{array}$ & $\begin{array}{c}\text { Desacordo } \\
\text { familiar }\end{array}$ \\
\cline { 2 - 3 } Idade (em anos) & n (\%) & n (\%) & n (\%) \\
$0-20$ & $2(2,5)$ & - & $4(6,5)$ \\
$21-40$ & $11(13,8)$ & $14(14,9)$ & $6(9,7)$ \\
$41-60$ & $40(50,0)$ & $42(44,7)$ & $24(38,7)$ \\
$61-80$ & $27(33,8)$ & $38(40,4)$ & $28(45,2)$ \\
$>80$ & - & - & - \\
Tipo de doação* & & & $58(89,2)$ \\
Córneas & $62(75,6)$ & $93(94,9)$ & $5(7,7)$ \\
Córneas e órgãos & $12(14,6)$ & $2(2,0)$ & $2(3,1)$ \\
Múltiplos órgãos (exceto & $8(9,8)$ & $3(3,1)$ & \\
córneas) & & & \\
\hline
\end{tabular}

Fonte: Elaboração própria

*n<472 pela omissão de informações.

Nota: Sinal convencional utilizado:

- Dado numérico igual a zero não resultante de arredondamento.

Na Tabela 3, apresenta-se a distribuição das informações em branco nos formulários das entrevistas aos familiares dos potenciais doadores de uma CIHDOTT.

Tabela 3 - Distribuição de informações em branco nos formulários dos potenciais doadores. Pelotas, Rio Grande do Sul, Brasil - jan 2008-dez 2014 (N=472)

\begin{tabular}{lc}
\hline Variável & n (\%) \\
\hline Hora do óbito & $373(79,0)$ \\
Motivo da não doação* & $126(26,7)$ \\
Município do entrevistado & $86(18,2)$ \\
Assinatura do responsável pelo atendimento & $46(9,7)$ \\
Município de nascimento do doador & $27(5,7)$ \\
Parente do doador & $25(5,3)$ \\
Idade do potencial doador & $11(2,3)$ \\
Situação conjugal do doador & $260(55,1)$ \\
Sexo do potencial doador & $4(0,8)$ \\
Data do óbito & $4(0,8)$ \\
Tipo de óbito & $2(0,4)$ \\
Tipo de doação & $2(0,4)$ \\
\hline
\end{tabular}

Fonte: Elaboração própria.

*Informação não encontrada na ficha e no prontuário.

\section{Discussão}

No presente estudo, os registros de uma CIHDOTT de um hospital de ensino possibilitaram identificar $74,9 \%$ de prevalência de negativa familiar para doação de órgãos, assemelhando-se a uma pesquisa realizada em 2014, no Rio Grande do Norte, cuja prevalência foi de 72,3\% (65 potenciais doadores) $)^{(3)}$. Ao longo dos anos, o esperado era observar, neste estudo, uma queda na quantidade de negativas familiares para doação de órgãos, tendo em vista 
o aprimoramento das abordagens. Durante o ano de 2017, no Brasil, foram registrados 10.629 casos de potencial doador, e um total de 7.214 não doadores. Dentre estes destacam-se a recusa familiar (2.740), como a principal causa, assim como parada cardíaca (1.232) e contraindicação médica $(1.550)^{(2)}$.

Entendendo a relevância do principal motivo para não doação, é preciso considerar a entrevista enquanto crucial nesse processo, a qual envolve conhecimento técnico, mas também o preparo emocional do entrevistador ${ }^{(7)}$. Em estudo desenvolvido na Bahia, o cuidado de enfermagem do potencial doador de órgão remete, na equipe participante da pesquisa, a sentimentos e crenças sobre morte e morrer, os quais incidem em negação, conflitos e distanciamento, podendo impactar negativamente na qualidade desse cuidado ${ }^{(15)}$.

Dessa forma, é fundamental que se proporcione aos profissionais de saúde espaços de discussão, capacitação e atualização sobre a abordagem da família para doação, além de estratégias para estabelecer vínculo, facilitar e desenvolver uma comunicação efetiva no decorrer do processo de doação de órgãos e tecidos para transplante. Além disso, é necessário o desenvolvimento de atividades que tenham a finalidade de promover o compartilhamento de experiências, assim como de boas práticas dos enfermeiros que atuam nesse processo com seus pares.

$\mathrm{Na}$ presente pesquisa, delineou-se um perfil sociodemográfico dos potenciais doadores de órgãos e tecidos. O sexo masculino (57,6\%), de 40 a 69 anos $(75,8 \%)$, casado $(29,2 \%)$ foi o perfil predominante, o que se aproxima de outros estudos ${ }^{(14,16)}$. A proveniência dos potenciais doadores foi maior no município da investigação $(55,5 \%)$ e os demais abrangeram a região. Dado semelhante foi identificado em outra pesquisa, na qual $57,14 \%$ eram procedentes do estado do Piauî́(13).

O tipo de óbito prevalente foi por parada cardiorrespiratória (85,2\%), sendo menos de 15\% identificado pela morte encefálica. No período compreendido entre 2010 e 2017, observou-se, por meio do Registro Brasileiro de Transplantes, que, no estado do Rio Grande do Sul, 97 (12\%) mortes foram por parada cardíaca e 57 (7\%) por morte encefálica ${ }^{(2)}$. Numa pesquisa em Santa Catariana com recusa familiar, houve predominância do sexo masculino, com 68\%, faixa etária dos 20 a 30 anos, e como causa da morte, 52\% por morte encefálica ${ }^{(17)}$. Frente a isso, deve-se considerar que o perfil epidemiológico do potencial doador foi sendo modificado ao longo dos anos; as mortes de origem traumáticas, por acidentes de trânsito e violência, estão entre as mais prevalentes. Além disso, tem-se um doador com idade maior e mais comorbidades crônicas.

A predominância de genitores, cônjuges, filhos e irmãos na entrevista familiar foi similar em outro estudo em Sergipe ${ }^{(14)}$. Numa investigação no Piauí, de 21 familiares que recusaram a doação, o grau de parentesco foi de 38,1\% de pais e $23,8 \%$ de filhos ${ }^{(13)}$. Em Sergipe, na entrevista familiar, os genitores $(35,3 \%)$ foram os principais envolvidos na recusa da doação ${ }^{(14)}$. $\mathrm{Na}$ presente investigação, o desconhecimento da vontade do potencial doador (20,8\%), a convicção prévia desse $(17,6 \%)$ e desacordos familiares $(13,8 \%)$ apresentaram-se como os motivos mais frequentes para a resposta negativa referente à doação de órgãos e tecidos.

Na literatura é mencionado que, entre 2008 e 2012, as causas mais citadas em publicações científicas para não doação foram, dentre outras, o desconhecimento do desejo do potencial doador e discordância familiar ${ }^{(18)}$. Noutro estudo, foi identificado que motivos como desconhecimento da vontade do falecido, respeito ao desejo desse de não ser doador e desacordos familiares estão entre os quatro primeiros fatores de recusa na abordagem familiar, os quais, juntos, somam $59,57 \%$ do total ${ }^{(4)}$. Considera-se importante o estudo $^{(9)}$ que apontou a necessidade de mais pesquisas sobre as vivências das famílias acerca da morte e do processo de decisão de doar ou não.

Num estudo em Sergipe, os principais motivos de recusa familiar foram, entre outros: $36,2 \%$ sem a informação, 26,7\% contrário à doação, 21,6\% desejo do corpo íntegro, 5,2\% desconhecimento do desejo do doador, $4,3 \%$ receio na demora da 
liberação do corpo, $1,7 \%$ convicção religiosa ${ }^{(14)}$. Noutra pesquisa, a recusa familiar decorreu de: divergência familiar (28,58\%), manutenção do corpo íntegro, o potencial doador não era doador em vida e o desconhecimento sobre o diagnóstico de morte encefálica $(14,28 \% \text { cada })^{(13)}$.

Outra investigação trouxe que 9,5\% das famílias entrevistadas tinham dúvida sobre a integridade do corpo, sendo esta a principal justificativa da negação ${ }^{(19)}$. Ainda, na avaliação das causas de recusa familiar, teve-se a convicção prévia, em 9\% da amostra, dúvida sobre a integridade do corpo, em 5,2\%, e desacordo familiar, em 3,4\%. Nesse contexto, foi evidenciado que 63\% dos entrevistados não tinham conhecimento da vontade do doador, $37 \%$ sabiam qual era o desejo do falecido e foram contrários à sua vontade. $\mathrm{Na}$ análise do grau de parentesco dos familiares com o potencial doador, 64\% eram parentes até segundo grau e 14\% eram cônjuges ${ }^{(5)}$.

Num hospital de Santa Catarina, 64,3\% das entrevistas tiveram a recusa familiar como resposta. Destas 48,4\% das famílias não concordaram com a doação ${ }^{(20)}$. Quanto ao perfil dos doadores elegíveis em morte encefálica, 52,4\% eram do sexo feminino ${ }^{(13)}$, assim como no presente estudo, em que $17,9 \%$ foram mulheres. Dentre os familiares que recusaram a doação, 61,9\% eram mulheres; $61,9 \%$ eram parentes de primeiro grau, sendo $38,9 \%$ pais, $23,8 \%$ filhos e $14,3 \%$ cônjuges e irmãos ${ }^{(13)}$. Quanto ao desejo de manter o corpo íntegro, 100\% dos familiares que recusaram a doação foram os pais. Quando o motivo alegado foi não ser doador em vida, 66,7\% dos familiares contrários à doação foram os filhos ${ }^{(14)}$.

De acordo com a legislação brasileira acerca do consentimento familiar, a "[...] autorização deverá ser do cônjuge, do companheiro ou de parente consanguíneo, de maior idade e juridicamente capaz, na linha reta ou colateral, até o segundo grau, e firmada em documento subscrito por duas testemunhas presentes à verificação da morte” ${ }^{(1)}$. Diante disso, é necessário atentar para quem poderá ser o familiar que consente ou recusa a doação, assim como o registro dessa informação de maneira adequada. No presente estudo, situações ligadas ao consentimento familiar foram de encontro à legislação.

Em relação aos achados da presente investigação e de demais estudos quanto aos motivos de negativa mencionados pelos familiares, a maioria pode ser modificada se ações de sensibilização e educação da população forem realizadas. Exemplos disso, são as inúmeras e diversas campanhas nas mídias que apontam para a necessidade de as pessoas dialogarem sobre o tema de doação na família. Assim, é fundamental que as pessoas entendam que não é suficiente se dizer doador; é necessário que os familiares sejam informados e estejam cientes do desejo, o que facilitará a tomada de decisão da família.

Num estudo desenvolvido em seis hospitais do Rio Grande do Norte, observou-se a falta de documentação e de registros como importante componente da estrutura organizacional para doação de órgãos e tecidos ${ }^{(3)}$. Entende-se que esse processo precisa ser bem conduzido, em cada etapa, e adequadamente documentado ${ }^{(21)}$. O preenchimento inadequado dos registros pode prejudicar a comunicação entre os multiprofissionais, assim como o cuidado contínuo prestado, a compreensão integral do paciente e, portanto, repercutir negativamente na segurança das ações e seu amparo legal ${ }^{(22)}$. É preciso que se entenda que são os documentos que relatam todas as atividades junto ao potencial doador e podem evidenciar a transparência e credibilidade do processo, para que a família tenha confiança na equipe.

No presente estudo, as informações ausentes nas fichas das entrevistas estavam relacionadas ao motivo da não doação (26,7\%), munícipio do entrevistado $(18,2)$, assinatura do responsável pela entrevista $(18,2 \%)$ e parente do doador $(5,3 \%)$. Na ficha do potencial doador, não constava a sua situação conjugal. Tais dados podem subsidiar o entrevistador e o preparo da equipe na abordagem das famílias. Noutra pesquisa, em Sergipe, 75\% dos prontuários apresentaram a realização de entrevista familiar, quando havia, e 36,2\% não tinham o registro do motivo da não doação ${ }^{(14)}$. 
Esses dados são fundamentais para a segurança e a tomada de decisão da família e também para o gerenciamento do processo, além da capacitação continuada dos profissionais sobre a importância de registros completos e fidedignos ${ }^{(14)}$. Nessa direção, a equipe é obrigada a notificar a ocorrência do óbito e a justificar a autorização ou negação da doação de órgãos e tecidos ${ }^{(23)}$. Para lidar com as fragilidades mencionadas, descreve-se o papel fundamental do enfermeiro, visto que da sua atuação transcorrem as fases do processo de doação e transplante de órgãos e tecidos, as quais envolvem aspectos assistenciais, de gestão e educacionais ${ }^{(24)}$.

$\mathrm{Na}$ presenta pesquisa, as respostas de outras variáveis do estudo, de suma importância para a identificação do possível doador, estavam em branco: hora do óbito (79\%), idade do potencial doador $(2,3 \%)$, data do óbito $(0,8 \%)$, tipo de óbito $(0,4 \%)$, tipo de doação $(0,4 \%)$. Em uma investigação no Rio de Janeiro, foi mencionado que informações como essas são imprescindíveis na abordagem familiar, já que o profissional necessita conhecer detalhes sobre o potencial doador para realizar a entrevista de modo singular, a cada caso, vislumbrando uma possível autorização da família para a doação de órgãos ${ }^{(7)}$.

Diante do exposto, torna-se importante também considerar os registros relacionados ao processo de doação e transplante, identificando suas fragilidades, a fim de proporcionar informações, suficientes e adequadas à gestão e aos profissionais envolvidos. Com isso, torna-se possível a elaboração de intervenções, o aprimoramento das políticas públicas e do próprio processo de trabalho, o que possibilitará o aumento efetivo de doações e, consequentemente, dos transplantes.

O limite deste estudo está na impossibilidade de generalização dos achados, pois o levantamento das recusas refere-se à realidade de um único momento no tempo, delimitado entre 2008 e 2014, cujo delineamento transversal não permite o estabelecimento de relações causais. Além disso, por se tratar de coleta de dados secundários em prontuários, algumas dificuldades, comuns nesse tipo de coleta, também aconteceram, a exemplo da ausência de informações em alguns campos, assim como a utilização de distintos formulários para os cadastros no decorrer dos anos.

Contudo, apesar de não representar a realidade de todas as CIHDOTT da região, este estudo permite subsidiar outras Comissões na busca dos problemas enfrentados de forma regional, para melhor compreensão da negativa de doação de órgãos e tecidos. Desse modo, outros estudos, com distintas abordagens metodológicas, precisam ser realizados, considerando aspectos culturais, sociais e políticos. Trata-se de um tema fundamental a ser explorado para direcionar ações com vistas à sensibilização da sociedade para tal prática.

\section{Conclusão}

O estudo possibilitou identificar o perfil sociodemográfico de familiares e potenciais doadores, a prevalência de negativa de familiares, assim como os principais motivos para a não doação de órgãos e tecidos. O motivo da recusa mais frequente foi o desconhecimento da opinião do doador pelo familiar responsável. Tal fato levanta a discussão de que, se aquela pessoa, em algum momento de sua vida, tivesse informado a sua família sobre o desejo de doar seus órgãos, provavelmente seus familiares teriam respeitado sua decisão.

Os achados do presente estudo podem contribuir para o direcionamento, planejamento e desenvolvimento de intervenções orientadas aos motivos que podem ser modificados, mediante o acesso à informação e sensibilização da população em relação ao tema, e assim elevar o número de doadores efetivos e transplantes, reduzindo a lista de espera por um órgão e/ou tecido. Ressalta-se que a realização de estudos epidemiológicos descritivos tem sido importante para caracterizar os motivos da negativa de doação de órgãos e tecidos para transplante. Dessa forma, esse tipo de abordagem pode ser uma das melhores estratégias de que se dispõe para direcionar ações de educação à população sobre o tema. Para atender à demanda de promover 
melhor entendimento, solidariedade e coparticipação frente à doação de órgãos e tecidos, é preciso a união de forças entre os hospitais e seus parceiros, tais como universidade, comunidade e sociedade.

Espera-se que os resultados desta pesquisa possibilitem o desenvolvimento de outros estudos sobre este tema, assim como que a família seja envolvida no processo de doação de órgãos e tecidos para transplante. Contudo, estas questões necessitam de uma abordagem que vá além dos aspectos biomédicos e inclua o social e o cultural, pois a participação da sociedade, das instituições de ensino, da mídia e do poder público é de suma importância, já que todos precisam estar em convergência para a obtenção de resultados benéficos para a divulgação deste tema.

\section{Colaborações:}

1. concepção, projeto, análise e interpretação dos dados: Renata Souza Aranda, Juliana Graciela Vestena Zillmer, Kamila Dias Gonçalves e Eduarda Rosado Soares;

2. redação do artigo e revisão crítica relevante do conteúdo intelectual: Renata Souza Aranda, Juliana Graciela Vestena Zillmer, Kamila Dias Gonçalves, Adrize Rutz Porto, Eduarda Rosado Soares e Aline Kohler Geppert;

3. aprovação final da versão a ser publicada: Renata Souza Aranda, Juliana Graciela Vestena Zillmer, Kamila Dias Gonçalves, Adrize Rutz Porto, Eduarda Rosado Soares e Aline Kohler Geppert.

\section{Referências}

1. Brasil. Decreto n. 9.175, de 18 de outubro de 2017. Regulamenta a Lei n. 9.434, de 4 de fevereiro de 1997, para tratar da disposição de órgãos, tecidos, células e partes do corpo humano para fins de transplante e tratamento [Internet]. Brasília; 2017 [cited 2018 Apr 12]. Available from: http://www. planalto.gov.br/ccivil_03/_ato2015-2018/2017/ decreto/D9175.htm

2. Associação Brasileira de Transplantes de Órgãos. Dimensionamento dos transplantes no Brasil e em cada estado (2010-2017). RBT [Internet]. 2017 [cited 2018 Mar 12];23;4:1-104. Available from: http://www.abto.org.br/abtov03/Upload/file/ RBT/2017/rbt-imprensa-leitura-compressed.pdf

3. Freire ILS, Vasconcelos QLDAQ, Torres GV, Araújo EC, Costa IKF, Melo GSM. Estrutura, processo e resultado da doação de órgãos e tecidos para transplante. Rev Bras Enferm [Internet]. 2015 [cited 2018 May 31];68(5):837-45. Available from: http:// www.scielo.br/pdf/reben/v68n5/0034-7167reben-68-05-0837.pdf

4. Rosário EN, Pinho LG, Oselame GB, Neves EB. Recusa familiar diante de um potencial doador de órgãos. Cad Saúde Colet [Internet]. 2013 [cited 2018 Feb 5];21(3):260-6. Available from: http:// www.scielo.br/pdf/cadsc/v21n3/v21n3a05.pdf

5. Pessoa JLE, Schirmer J, Roza BA. Avaliação das causas de recusa familiar à doação de órgãos e tecidos. Acta paul enferm [Internet]. 2013 [cited 2015 Feb 5];26(4):323-30. Available from: http:// www.scielo.br/pdf/ape/v26n4/v26n4a05.pdf

6. Bonetti CE, Boes AA, Lazzari DD, Busana JA, Maestri E, Bresolin P. Doação de órgãos e tecidos e motivos de sua não efetivação. Rev enferm UFPE on line. 2017 [cited 2018 May 10];11(Sup19):3533-41. Available from: https://periodicos.ufpe.br/revistas/ revistaenfermagem/article/view/234483/27676

7. Fonseca PIMN, Tavares CMM, Silva TN, Paiva LM, Augusto VO. Entrevista familiar para doação de órgãos: conhecimentos necessários segundo coordenadores em transplantes [Internet]. Rev pesqui cuid fundam [Internet]. 2016 [cited 2018 Mar 10];8(1):3979-90. Available from: http://www. seer.unirio.br/index.php/cuidadofundamental/ article/view/4985/pdf_1821

8. Leite NF, Maranhão TLG, Farias AA. Captação de múltiplos órgãos: os desafios do processo para os profissionais da saúde e familiares. Id on Line Rev Psic [Internet]. 2017 [cited 2018 May 11];11(34):24770. Available from: https://idonline.emnuvens. com.br/id/article/view/687/967

9. Rossato GC, Girardon-Perlini NMO, Begnini D, Beuter M, Camponogara S, Flores CL. Donate or not to donate: the view of the family before the organ donation. Rev Min Enferm [Internet]. 2017 [cited 2018 Sep 20];21:e-1056. Available from: http://www.reme.org.br/artigo/detalhes/1194

10. Chieratto CLD, Gonsaga RAT, Vidal B. Impacto da disponibilidade de profissional com dedicação exclusiva no processo de doação de órgãos. J Health 
Sci [Internet]. 2017 [cited 2018 Sep 19];19(4):25661. Available from: http://pgsskroton.com.br/seer/ index.php/JHealthSci/article/view/3968/3716

11. Silva SL, Oliveira ILF, Pego ZO, Pereira JR, Sousa CV. Condicionantes da motivação para a doação de órgãos: uma análise à luz do marketing social. Teoria Prática Adm [Internet]. 2016 [cited 2018 Sep 19];6(1):69-96. Available from: http:// periodicos.ufpb.br/ojs/index.php/tpa/article/ view/28274/15651

12. Siqueira MM, Araujo CA, Roza BA, Schirmer J. Indicadores de eficiência no processo de doação e transplante de órgãos: Revisão sistemática da literatura. Rev Panam Salud Publica [Internet]. 2016 [cited 2018 Sep 19];40(2):90-7. Available from: http://iris.paho.org/xmlui/bitstream/handle/ 123456789/31162/v40n2a5_90-97.pdf?sequence=1

13. Figueiredo PHV, Moura LC, Carvalho AMC. Doação de órgãos para transplante: análise dos doadores elegíveis e recusa familiar. RBM Transplantes [Internet]. 2016 [cited 2018 Mar 14];73(n esp):13-9. Available from: http://www.moreirajr.com.br/ revistas.asp?fase $=$ r003\&id_materia $=6329$

14. Barreto BS, Santana RJB, Nogueira EC, Fernandez $\mathrm{BO}$, Brito FPG. Fatores relacionados à não doação de órgãos de potenciais doadores no estado de Sergipe, Brasil. Rev Bras Pesq Saúde [Internet]. 2016 [cited 2018 May 29];18(3):40-8. Available from: http://periodicos.ufes.br/RBPS/article/download/ 15741/10888

15. Almeida AM, Carvalho ESS, Cordeiro GM. Cuidado ao potencial doador: percepções de uma equipe de enfermagem. Rev baiana enferm [Internet]. 2015 out/dez [cited 2018 June 1];29(4):328-38. Available from: https://portalseer.ufba.br/index. php/enfermagem/article/view/13641/pdf_14

16. Freire ILS, Silva MF, Gomes ATL, Dantas BAS, Torres GV. Caracterização dos potenciais doadores e estrutura de unidades hospitalares que desenvolvem o transplante. Ciênc Cuid Saúde [Internet]. 2015 [cited 2016 Jan 10];14(3):1281-9. Available from: http://www.periodicos.uem. br/ojs/index.php/CiencCuidSaude/article/ view/22819/15276

17. Silva OM, Kolhs M, Ascari RA, Ferraboli S, Kessler M, Muniz T. Perfil de doadores de um hospital público do Oeste de Santa Catarina. J res: fundam care online. 2014 [cited 2018 May 20];6(4):1534-45. Available from: http://www. redalyc.org/pdf/5057/505750770019.pdf
18. Brito LD, Prieb RG. Fatores de interferência no processo de doação de órgãos e tecidos: revisão da literatura. J Bras Transpl [Internet]. 2012 [cited 2014 Nov 20];15(2):1676-81. Available from: http://www.abto.org.br/abtov03/Upload/file/ JBT/2012/2.pdf

19. Pompeu MH, Silva SS, Roza BA, Bueno SMV. Fatores envolvidos na negativa da doação de tecido ósseo. Acta Paul Enferm [Internet]. 2014 [cited 2015 Jan 15];27(4):380-4. Available from: http://www.scielo. br/pdf/ape/v27n4/1982-0194-ape-027-004-0380. pdf

20. Knihs NS, Roza BA, Schirmer J, Ferraz AS. Aplicação de instrumentos de qualidade em doação de órgãos e transplantes da Espanha validados em hospitais pilotos em Santa Catarina. J Bras Nefrol [Internet]. 2015 [cited 2017 Mar 20];37(3):323-32. Available from: http://www.scielo.br/pdf/jbn/ v37n3/0101-2800-jbn-37-03-0323.pdf

21. Magalhaes ALP, Melo GMM, Knihs NS, Silva EL, Erdmann AL. Segurança do paciente no processo de doação e transplante de órgãos e tecidos. Cogitare Enferm. 2017 [cited em 29 Apr 2018];22(2):e45621. Available from: https://revistas.ufpr.br/cogitare/ article/view/45621/pdf

22. Conselho Regional de Enfermagem. Anotações de enfermagem. São Paulo; jun 2009 [cited 2018 Apr 30]. Available from: http://inter.corensp.gov. $\mathrm{br} /$ sites/default/files/ anotacoes_enfermagem.pdf

23. Brasil. Ministério da Saúde. Portaria n. 1.752, de 23 de setembro de 2005. Determina a constituição de Comissão Intra-Hospitalar de Doação de Órgãos e Tecidos para Transplante em todos os hospitais públicos, privados e filantrópicos com mais de 80 leitos [Internet]. Brasília; 2005 [cited 25 Dec 2017]. Available from: http://bvsms.saude.gov.br/bvs/ saudelegis/gm/2005/prt1752_23_09_2005.html

24. Mendes KDS, Roza BA, Barbosa SFF, Schirmer J, Galvão CM. Transplante de órgãos e tecidos: responsabilidades do enfermeiro. Texto Contexto Enferm [Internet]. 2012 [cited 2018 Sep 20];21(4):945-53. Available from: http://www. scielo.br/pdf/tce/v21n4/27.pdf

Recebido: 6 de agosto de 2018 Aprovado: 27 de outubro de 2018 Publicado: 27 de dezembro de 2018 
A Revista Baiana de Enfermagem utiliza a Licença Creative Commons - Atribuição-NãoComercial 4.0 Internacional. https://creativecommons.org/licenses/by-nc/4.0/

Este artigo é de acesso aberto distribuído sob os termos da Licença Creative Commons (CC BY-NC).

Esta licença permite que outros remixem, adaptem e criem a partir do seu trabalho para fins não comerciais. Embora os novos trabalhos tenham de lhe atribuir o devido crédito e não possam ser usados para fins comerciais, os usuários não têm de licenciar esses trabalhos derivados sob os mesmos termos. 